\title{
Connection Problem
}

National Cancer Institute

\section{Source}

National Cancer Institute. Connection Problem. NCI Thesaurus. Code C62952.

Problem associated with linking of a device and/or the functional units set up to provide means for a transfer of liquid, gas, electricity or data. 